\title{
El derecho de acceso a la información pública: contenido e importancia
}

\author{
Yvana Lucía Novoa Curich
}

En el presente artículo, la autora resolverá las interrogantes respecto a la relación entre el Estado y la ciudadanía. Asimismo, analizará el rol del acceso a la información pública de acuerdo a la importancia que éste tiene en un Estado democrático a partir del marco jurídico nacional e internacional.

Abogada por la Pontificia Universidad Católica del Perú (PUCP). Segunda especialidad en Derecho Público y Buen Gobierno por la misma casa de estudios. Post - título en Transparencia, Accountability y Lucha contra la corrupción por la Universidad de Chile. Miembro del Grupo de Investigación en Derecho Penal y Corrupción (DEPEC). Ha sido Investigadora del Área Anticorrupción del Instituto de Democracia y Derechos Humanos de la PUCP. Actualmente es Abogada Monitor del Centro de Información Abierta Liber. 


\section{El derecho de acceso a la información pública: contenido e importancia}

En un Estado social y democrático de Derecho, todas las instituciones públicas deben estar, por definición, al servicio de la ciudadanía. Es decir, se deben a la población en el ejercicio de su función. Es por ello que resulta contradictorio que un Estado como el peruano haya vivido tantos años - y aún mantenga rezagos- de la cultura del secreto en el seno de sus entidades e instituciones.

En este contexto, adquiere especial relevancia el derecho fundamental de acceso a la información pública, pues su contracara es la obligación estatal de brindar información que esté en su posesión cuando un ciudadano la solicite, sin expresión alguna de causa.

El derecho de acceso a información pública no es solo un derecho, es una herramienta indispensable para la satisfacción de otros derechos y principios constitucionales, así como para el diseño y ejecución de políticas y mecanismos de prevención de la corrupción. Todo lo cual resulta imperioso al interior de un Estado como el peruano; el cual, a lo largo de su historia, no se ha caracterizado especialmente por la protección de derechos humanos ni por la probidad en el ejercicio de la función pública por parte de sus autoridades.

\section{Contenido del derecho de acceso a información pública}

El derecho de acceso a la información pública es un derecho fundamental con autonomía. No obstante, se le considera una especie que se desprende del derecho a la información. Es un derecho que consiste en que toda persona puede pedir información que se encuentra en posesión de las instituciones y organismos del Estado $y$, por consiguiente, este debe entregar la información allí donde la información solicitada no se encuentre protegida por algunos de los supuestos de excepciones previstos en la Constitución o en la Ley 27806, Ley de Transparencia y Acceso a la Información Pública (en adelante LTAIP) ${ }^{1}$. En otras palabras, es el derecho que tiene todo individuo a que toda entidad que ejerce funciones públicas -comprendiendo la información que produzcan o posean las empresas privadas que prestan servicios públicos- proporcione o brinde la información que un ciudadano solicite, la cual puede haber sido producida por dicha entidad o estar en poder de esta aunque no la haya producido de manera directa².

1 Rubio, Marcial, et al., Los derechos fundamentales en la jurisprudencia del Tribunal Constitucional: Análisis de los artículos 1, 2 y 3 de la Constitución, Fondo Editorial de la Pontificia Universidad Católica del Perú, Lima, 2013, p. 279.

2 Defensoría del Pueblo, El acceso a la Información Pública: no a la cultura del secreto, Defensoría del Pueblo, Lima, 2001, pp. 12-13. 
Según el Tribunal Constitucional, este derecho "en su faz positiva (...) impone a los órganos de la Administración pública el deber de informar». De otro lado, «en su faz negativa, exige que la información que se proporcione no sea falsa, incompleta, fragmentaria, indiciaria o confusa"' ${ }^{3}$.

La Corte Interamericana de Derechos Humanos, en la sentencia del caso Claude Reyes, se pronunció sobre el contenido de este derecho:

"77. En lo que respecta a los hechos del presente caso, la Corte estima que el artículo 13 de la Convención, al estipular expresamente los derechos a "buscar" y a "recibir" "informaciones", protege el derecho que tiene toda persona a solicitar el acceso a la información bajo el control del Estado, con las salvedades permitidas bajo el régimen de restricciones de la Convención. Consecuentemente, dicho artículo ampara el derecho de las personas a recibir dicha información y la obligación positiva del Estado de suministrarla, de forma tal que la persona pueda tener acceso a conocer esa información o reciba una respuesta fundamentada cuando por algún motivo permitido por la Convención el Estado pueda limitar el acceso a la misma para el caso concreto. Dicha información debe ser entregada sin necesidad de acreditar un interés directo para su obtención o una afectación personal, salvo en los casos en que se aplique una legítima restricción. Su entrega a una persona puede permitir a su vez que ésta circule en la sociedad de manera que pueda conocerla, acceder a ella y valorarla. $(\ldots)^{\prime \prime 4}$.

Por otra parte, es pertinente señalar que incluso en aquellos casos en que la entidad pública no cuente con la información solicitada pero sabe dónde se encuentra esta, debe indicar al particular interesado a fin de que este se dirija a la entidad u organismo que pueda brindarle la información.

El derecho de acceso a información pública encuentra sus cimientos en el principio de publicidad, también conocido como principio de máxima divulgación, por el cual toda información que se encuentre en posesión del Estado se presume pública y, por lo tanto, debe estar al alcance de los ciudadanos. Resulta ser un principio fundamental para sociedades democráticas ${ }^{5}$, las cuales, a su vez, se sostienen sobre la premisa de

3 Sentencia del Tribunal Constitucional recaída en el Expediente 1791-2002-HD/TC, fundamento 16 .

$4 \quad$ Sentencia de la Corte Interamericana de Derechos Humanos, recaída en el caso Claude Reyes y otros, emitida el 19 de setiembre de 2006.

5 Corte Interamericana de Derechos Humanos, El derecho de acceso a la información pública en las Américas: Estándares interamericanos y comparación de marcos legales, Relatoría Especial para la Libertad de Expresión, 2012, pp. 5-6. 
que el poder del Estado emana del pueblo y es a este a quien el Estado está en obligación de rendir cuentas -en un sentido amplio- o de responder sobre sus actos. Consecuentemente, esto se traduce en la obligación del Estado de entregar la información que se le solicita. Este principio se encuentra previsto en el artículo 3 de la LTAIP:

"Todas las actividades y disposiciones de las entidades comprendidas en la presente Ley están sometidas al principio de publicidad.

Los funcionarios responsables de brindar la información correspondiente al área de su competencia deberán prever una adecuada infraestructura, así como la organización, sistematización y publicación de la información a la que se refiere esta Ley.

\section{En consecuencia:}

1. Toda información que posea el Estado se presume pública, salvo las excepciones expresamente previstas por el artículo 15 de la presente Ley.

2. El Estado adopta medidas básicas que garanticen y promuevan la transparencia en la actuación de las entidades de la Administración Pública.

3. El Estado tiene la obligación de entregar la información que demanden las personas en aplicación del principio de publicidad.

La entidad pública designará al funcionario responsable de entregar la información solicitada".

En otras palabras, el principio de máxima divulgación o publicidad debe ser entendido como un "proceso de socialización y comunicación de cosas, ideas y proyectos (...) esencial en las sociedades modernas, (...) aparece como un mecanismo de control racional para evitar que las informaciones y argumentos de la vida política se conviertan en (...) defensa de lo injusto o justificaciones de la violación de derechos y libertades de los ciudadanos ${ }^{\prime \prime 6}$. Como puede apreciarse, el principio de publicidad resulta una obligación estatal en el ejercicio de su función legislativa y también como parámetro de evaluación de la legitimidad de las razones o motivaciones que brinda para sustentar sus decisiones ${ }^{7}$.

$6 \quad$ Rodríguez Cepeda, Jesús, "El derecho de acceso a la información pública". En: Boletín Informativo Mensual, n. 38, 2014, p. 36-39.

7 Rodríguez Cepeda, Jesús, "El derecho de acceso a la información pública". En: Boletín Informativo Mensual, n. 38, 2014, p. 40. 
Ahora bien, el derecho de acceso a información pública puede ser entendido desde dos dimensiones, las cuales han sido expuestas por el Tribunal Constitucional peruano. Por un lado, se encuentra la dimensión individual y, por otro, la dimensión colectiva. La primera consiste en garantizar que no se impida a una persona, de forma arbitraria el acceso a la información que las entidades estatales guarden, tengan o elaboren. El derecho en análisis solo puede verse limitado por las excepciones mencionadas en la Constitución. Dentro de esta dimensión individual se encuentra también el carácter instrumental del derecho de acceso a la información, es decir, el derecho de acceso a información pública es necesario para poder satisfacer otros derechos fundamentales y, de esto se expondrá más adelante. Así, en la sentencia recaída en el Expediente 05624-2009-PHD/TC, del 1 de diciembre de 2010, el Tribunal Constitucional indicó que:

"Debe indicarse que el derecho de acceso a la información pública tiene una doble dimensión. Por un lado, se trata de un derecho individual, en el sentido de que garantiza que nadie sea arbitrariamente impedido de acceder a la información que guarden, mantengan o elaboren las diversas instancias y organismos que pertenezcan al Estado, sin más limitaciones que aquellas que se han previsto como constitucionalmente legítimas. A través de este derecho se posibilita que los individuos, aisladamente considerados, puedan trazar, de manera libre, su proyecto de vida, pero también el pleno ejercicio y disfrute de otros derechos fundamentales. Desde esta perspectiva, en su dimensión individual, el derecho de acceso a la información se presenta como un presupuesto o medio para el ejercicio de otras libertades fundamentales, como puede ser la libertad de investigación, de opinión o de expresión, por mencionar alguna".

Por otra parte, en cuanto a la dimensión colectiva, el acceso a la información pública consiste en que todas las personas tienen derecho a recibir información necesaria y oportuna a fin de que se pueda formar la opinión pública libre e informada, la cual es requisito esencial en un sistema democrático como herramienta fundamental para el control ciudadano pleno o real sobre la actuación estatal ${ }^{8}$.

Entonces, puede afirmarse que la información que poseen las instituciones estatales conforman un verdadero bien público que debe estar al alcance de cualquier persona con el objetivo de que los principios de máxima divulgación y transparencia se realicen de modo efectivo; pero también como un canal de control de las autoridades e instituciones ${ }^{9}$.

8 Sentencia del Tribunal Constitucional recaída en el Expediente 1797-2002-HD/TC, emitida el 29 de enero del 2003, fundamentos 10-11.

9 Sentencia del Tribunal Constitucional recaída en el Expediente 5624-2009-PHD/TC, emitida el 1 de diciembre del 2010, fundamentos 5-6. 


\subsection{El derecho de acceso a la información pública y el principio de transparencia}

La transparencia en un sentido amplio, puede ser comprendida como apertura de la comunicación. Desde una perspectiva más concreta, consiste en la apertura que debe tener el trabajo del gobierno frente a los ciudadanos ${ }^{10}$. Al respecto, es pertinente resaltar lo indicado por Radha Ivory cuando considera que la transparencia es aquella manera que tiene un gobierno de comportarse de acuerdo a reglas fijas y públicas, sobre la base de información y procedimientos accesibles al público en general ${ }^{11}$.

En este orden de ideas, se trata de un deber estatal de cara a sus ciudadanos. Dicho deber encuentra su razón de ser en el fundamento mismo de la existencia del Estado: este último se encuentra al servicio de los individuos ${ }^{12}$, tal y como ha sido mencionado ya y como lo establece la Constitución en su artículo 390. El contexto global en que se vive ha significado la necesidad de los Estados de interrelacionarse con nuevos actores en la arena pública global. Los Estados han dejado de ser el centro de las tomas de decisión y de solución de problemáticas. Entre estos actores se encuentra la ciudadanía, de la cual proviene el poder del Estado y hacia la cual este último debe mirar cuando actúa o toma alguna decisión. Siendo esto así, es absolutamente lógico que los poderes públicos tengan la obligación de ser transparentes y de no ocultar, en principio, ningún tipo de información relevante para la ciudadanía.

Es así que la transparencia, como principio que rige la actuación del Estado, debe ser analizada y entendida desde dos dimensiones: a) transparencia activa, y b) transparencia pasiva, como se expone a continuación:

- Transparencia activa.- Consiste en que las entidades de los poderes públicos tienen la obligación de poner a disposición del público en general y de manera proactiva, determinada información actualizada (por ejemplo, organización, funciones, marco normativo,

Addink, Henk, Good governance: concept and context, Oxford University Press (Draft), Oxford, 2013, p. 74.

IVORY, Radha, Transparency and opacity in the United Nations Convention Against Corruption. Citado por: CASTRO, Alberto. Buen Gobierno y derechos humanos. Nuevas perspectivas en el derecho público para fortalecer la legitimidad de la administración pública en el Perú. Facultad de Derecho PUCP. Lima. 2014. p. 147.

12 Rodríguez Cepeda, Jesús. "Estado y Transparencia: Un paseo por la filosofía política". En: Cuadernos de transparencia, n. 4, 2004, p. 31. 
etc.). Esta debe ser publicada en los portales electrónicos institucionales ${ }^{13}$.

- Transparencia pasiva.- Obligación que tienen los funcionarios y entidades de los poderes públicos de brindar o entregar información en virtud de una solicitud de acceso a información pública que un ciudadano o ciudadana presente por propia iniciativa ante dicha entidad o funcionario ${ }^{14}$.

Como puede apreciarse, el ejercicio del derecho de acceso a la información pública corresponde al plano de la dimensión pasiva del principio de transparencia. Este último es indesligable del derecho de acceso a la información pública. Uno no puede ser entendido sin el otro. En esta misma línea, "transparency is closely tied to the principles of participation, accountability, and effectiveness in democracy: people need information to formulate their preferences, express informed opinions, and influence decision-making; decision-makers need to be under obligations to justify and explain the conduct to which than information relates ${ }^{15}$.

\section{2 ¿Qué información se considera pública?}

La Ley de Transparencia y Acceso a la Información Pública establece en su artículo 10 que:

"Las entidades de la Administración Pública tienen la obligación de proveer la información requerida si se refiere a la contenida en documentos escritos, fotografías, grabaciones, soporte magnético o digital, o en cualquier otro formato, siempre que haya sido creada u obtenida por ella 0 que se encuentre en su posesión o bajo su control.

Asimismo, para los efectos de esta Ley, se considera como información pública cualquier tipo de documentación financiada por el presupuesto público que sirva de base a una decisión de naturaleza administrativa, así como las actas de reuniones oficiales".

13 Rodríguez Vásquez, Julio, et al. "El derecho de acceso a la información pública". En: Boletín Informativo Mensual, n. 38, 2014, p. 8. Boletín Informativo Mensual, n. 38, 2014, p. 8. perspectivas en el derecho público para fortalecer la legitimidad de la administración pública en el Perú. Facultad de Derecho PUCP. Lima. 2014. pp. 150-151. 
Es decir, los ciudadanos pueden solicitar ante una entidad pública información que haya sido producida por esta o que se encuentre en su poder a pesar de que no la haya producido de manera directa.

En relación al segundo párrafo del citado artículo, es necesario aclara que dicha disposición no puede ser interpretada como que solo se podrá pedir información que haya sido financiada por el presupuesto público. El término "asimismo" sirve para entender que el financiamiento de la información es un supuesto adicional a los del primer párrafo, se trata de un factor adicional que permite determinar cuándo se está ante información de carácter público. Al respecto, el Tribunal Constitucional ha establecido que: «la exigencia de que la documentación se encuentre financiada por el presupuesto público es irrazonablemente restrictiva de aquello que debe considerarse como «información pública». Lo realmente trascendental, a efectos de que pueda considerarse como «información pública», no es su financiación, sino la posesión y el uso que le imponen los órganos públicos en la adopción de decisiones administrativas, salvo, claro está, que la información haya sido declarada por ley como sujeta a reserva».

En apoyo a esta postura, la Defensoría del Pueblo considera que:

"conviene recordar que, en estricto, toda la información en poder de las administraciones se rige por el principio de publicidad, según el cual, la información en poder del Estado se presume pública. De esta obligación general de publicidad y su correspondiente presunción, se deriva que la obligación de entregar información por parte de las entidades se genera con la mera posesión de la información solicitada"16

Sobre qué información puede ser entregada por el Estado, es importante dejar en resaltar que la LTAIP, en su artículo 13, indica que la Administración Pública no se encuentra en obligación de crear o producir información que no posea o que no tenga obligación de contar cuando se realiza el pedido. En consecuencia, tampoco es posible que un ciudadano solicite a la entidad pública que esta desarrolle evaluaciones o un trabajo de análisis de la información que tenga bajo su poder. El análisis y procesamiento de la información debe ser llevado a cabo por el solicitante de acuerdo a los fines que lo llevaron a ingresar su solicitud de acceso a información pública. Esto no quiere decir que el solicitante deba dar explicaciones o motivar las razones por las cuales quiere acceder a determinada información. Por el contrario, la Constitución es

16 Defensoría del Pueblo, Informe Defensoría 96: Balance a dos años de vigencia de la Ley de Transparencia y Acceso a la Información Pública, Lima, 2005, p. 20. Disponible en: http://www.defensoria.gob.pe/temas.php?des=8. Última fecha de consulta: 29 de octubre de 2016. 
clara al señalar que el derecho consiste en solicitar información "sin expresión de causa".

Adicionalmente, es importante señalar las características que debe tener la información que el Estado entregue a los ciudadanos, a fin de que se considere plenamente satisfecho el derecho. En primer lugar, la información debe ser veraz, es decir, no debe ser falsa ni contener una versión o verdad a medias. También debe ser información completa, por lo cual la entidad pública no puede entregar solo algunas partes de la información que se pide, si es que no se encaja en alguna excepción legítima. La información debe ser actual, comprendiendo incluso aquellos datos que han podido surgir luego de que se presenta la solicitud de acceso y antes de que la información sea brindada. De igual forma, debe entregarse información precisa y concreta en relación con el requerimiento. Finalmente, la información no puede ser indiciaria (dando solo algunas luces o rastros) sino que debe informarse sobre los hechos concretos a los que el pedido hace referencia ${ }^{17}$. Todas estas características han sido establecidas también por el Tribunal Constitucional al indicar que "(...) si en su faz positiva el derecho de acceso a información impone a los órganos de la Administración pública el deber de informar, en su faz negativa, exige que la información que se proporcione no sea falsa, incompleta, fragmentaria, indiciaria o confusa"18.

\section{Regulación en el ordenamiento interno}

El derecho de acceso a la información pública se encuentra contemplado en el artículo 2 inciso 5 de la Constitución, del siguiente modo:

"Toda persona tiene derecho a:

5. A solicitar sin expresión de causa la información que requiera y a recibirla de cualquier entidad pública, en el plazo legal, con el costo que suponga el pedido. Se exceptúan las informaciones que afectan la intimidad personal y las que expresamente se excluyan por ley o por razones de seguridad nacional".

Asimismo, la Constitución dispone en su artículo 200, inciso 3 que es una garantía constitucional la acción de Hábeas Data, la cual "procede contra el hecho u omisión, por parte de cualquier autoridad, funcionario o persona, que vulnera o amenaza los derechos a que se refiere el artículo 2 , incisos 5 y 6 " del texto constitucional.

17 Rubio, Marcial, et al., Los derechos fundamentales en la jurisprudencia del Tribunal Constitucional: Análisis de los artículos 1, 2 y 3 de la Constitución, Fondo Editorial de la Pontificia Universidad Católica del Perú, Lima, 2013, p. 283.

18 Sentencia del Tribunal Constitucional, recaída en el Expediente 1797-2002-HD/TC, emitida el 29 de enero del 2003. 
En relación al proceso constitucional de Habeas Data, su regulación se encuentra desarrollada en el Código Procesal Constitucional en el Título IV. Dicho cuerpo normativo establece en su artículo 61 que:

"El hábeas data procede en defensa de los derechos constitucionales reconocidos por los incisos 5) y 6) del artículo 2 de la Constitución. En consecuencia, toda persona puede acudir a dicho proceso para:

1) Acceder a información que obre en poder de cualquier entidad pública, ya se trate de que la generen, produzcan, procesen o posean, incluida la que obra en expedientes terminados o en trámite, estudios, dictámenes, opiniones, datos estadísticos, informes técnicos y cualquier otro documento que la administración pública tenga en su poder, cualquiera que se ala forma de expresión, ya sea gráfica, sonora, visual, electromagnética o que obre en cualquier otro tipo de soporte material".

Es decir, el proceso constitucional de Habeas Data tiene la finalidad de hacer valer el derecho de acceso a la información pública cuando un ciudadano ha solicitado información a alguna entidad del Estado y esta ha rechazado total o parcialmente el pedido. A través de este proceso constitucional, el Poder Judicial o, en su momento, el Tribunal Constitucional, determinarán si la información solicitada fue adecuadamente clasificada como reservada o confidencial; es decir, si encaja correctamente en alguna de las excepciones previstas en la Constitución y desarrolladas por la LTAIP.

Por su parte, este derecho se encuentra plenamente desarrollado en la Ley 27806 LTAIP en cuyo artículo 1 se establece que:

"Artículo 1.- Alcance de la Ley

La presente Ley tiene por finalidad promover la transparencia de los actos del Estado y regular el derecho fundamental del acceso a la información pública consagrado en el numeral 5 del artículo 2 de la Constitución Política del Perú.

El derecho de acceso a la información pública de los Congresistas de la República se rige conforme a lo dispuesto por la Constitución Política del Perú y el Reglamento del Congreso".

\section{Regulación en el ordenamiento internacional}

El derecho de acceso a la información pública es un derecho humano y, en ese sentido, encuentra protección en el ordenamiento internacional a través de diversos instrumentos internacionales de los que el Estado peruano es parte.

Así, la Declaración Universal de Derechos Humanos dispone en su artículo $19^{\circ}$ señala que: "Todo individuo tiene derecho a la libertad de opinión y de expresión; este derecho incluye el de no ser molestado a causa de sus opiniones, el de investigar y 
recibir informaciones y opiniones, y el de difundirlas, sin limitación de fronteras, por cualquier medio de expresión".

De la misma forma, el Pacto Internacional de Derechos Civiles y Políticos indica lo siguiente:

"Artículo $19^{\circ}$.-

1. Nadie podrá ser molestado a causa de sus opiniones.

2. Toda persona tiene derecho a la libertad de expresión; este derecho comprende la libertad de buscar, recibir y difundir informaciones e ideas de toda índole, sin consideración de fronteras, ya sea oralmente, por escrito o en forma impresa o artística, o por cualquier otro procedimiento de su elección.

3. El ejercicio del derecho previsto en el párrafo 2 de este artículo entraña deberes y responsabilidades especiales. Por consiguiente, puede estar sujeto a ciertas restricciones, que deberán, sin embargo, estar expresamente fijadas por la ley y ser necesarias para:

a) Asegurar el respeto a los derechos o a la reputación de los demás;

b) La protección de la seguridad nacional, el orden público o la salud o la moral públicas".

En un sentido similar, la Convención Americana de Derecho Humanos tutela a través de su artículo 13:

"Artículo 13. Libertad de Pensamiento y de Expresión

1. Toda persona tiene derecho a la libertad de pensamiento y de expresión. Este derecho comprende la libertad de buscar, recibir y difundir informaciones e ideas de toda índole, sin consideración de fronteras, ya sea oralmente, por escrito o en forma impresa o artística, o por cualquier otro procedimiento de su elección.

2. El ejercicio del derecho previsto en el inciso precedente no puede estar sujeto a previa censura sino a responsabilidades ulteriores, las que deben estar expresamente fijadas por la ley y ser necesarias para asegurar:

a) el respeto a los derechos o a la reputación de los demás, o

b) la protección de la seguridad nacional, el orden público o la salud o la moral públicas. (...)".

Por otro lado, cabe destacar la existencia de documentos que, si bien no tienen carácter vinculante u obligatorio pues no se constituyen tratados internacionales, sí son relevantes y deben ser tomados en cuenta a fin de reforzar la tutela del derecho de 
acceso a información pública y de interpretar las normas internas e internacionales de un modo garantista de cara a la plena vigencia del derecho en análisis.

Pues bien, en el marco de la Organización de Estados Americanos (OEA), se cuenta con la Ley Modelo Interamericana sobre Acceso a la Información, la cual se configura como la norma o ley marco sobre la base de la cual se ha elaborado la LTAIP peruana. Un aspecto destacable de esta Ley Modelo es la disposición referida a que "las autoridades públicas podrán entregar la información de manera totalmente gratuita, incluyendo los costos de reproducción y envío, para cualquier ciudadano cuyos ingresos anuales sean menores a una cantidad establecida por la autoridad encargada de la transparencia del Estado"19. Asimismo, la Ley Modelo contiene las excepciones por las cuales determinada información que posea el Estado no deberá ser entregada. La LTAIP peruana ha recogido todas esas excepciones y, en este orden de ideas, la Ley Modelo Interamericana constituye un parámetro de interpretación de los alcances de la LTAIP para Perú.

En el ámbito internacional se encuentra también la Declaración de Principios sobre la Libertad de Expresión de la Comisión Interamericana de Derechos Humanos, la cual define el derecho en análisis en el siguiente sentido: "El acceso a la información en poder del Estado es un derecho fundamental de los individuos. Los Estados están obligados a garantizar el ejercicio de este derecho. Este principio solo admite limitaciones excepcionales que deben estar establecidas previamente por la ley para el caso que exista un peligro real e inminente que amenace la seguridad nacional en sociedades democráticas".

\section{Importancia y fundamento del derecho de acceso a información}

El derecho de acceso a la información pública constituye una herramienta fundamental para el sostenimiento de un sistema democrático por diversas razones que serán explicadas a continuación.

\subsection{El derecho de acceso a información pública como libertad preferida}

En el ordenamiento jurídico interno existen derechos o libertades que por la función que cumplen de cara a la protección del sistema democrático, son consideradas libertades preferidas. Estas últimas serían la libertad de expresión, libertad de información y el derecho de acceso a la información pública. Esto no quiere decir que dichos derechos tengan un valor u ocupen un grado superior en una escala jerárquica

19 Rodríguez Vásquez, Julio, et al, El derecho de acceso a la información pública, Instituto de Democracia y Derechos Humanos de la Pontificia Universidad Católica del Perú, Lima. Disponible en: http://idehpucp.pucp.edu.pe/wp-content/uploads/2012/07/comentarioacademico.pdf. Última fecha de consulta: 29 de octubre de 2016. 
de derechos. Todos los derechos fundamentales tienen el mismo valor y, de hecho, así lo ha establecido el Tribunal Constitucional en el conocido caso Wilo Rodríguez:

"Esta condición (...) no quiere decir que al interior de la Constitución exista un orden jerárquico entre los derechos fundamentales que ella reconoce, en la cúspide del cual se encuentre o pueda encontrarse el derecho de acceso a la información u otros derechos que cuentan igualmente con idéntica condición. $Y$, en ese sentido, que una colisión de éste con otros derechos fundamentales se resuelva en abstracto, haciendo prevalecer al que tiene la condición de libertad preferida. Evidentemente ello no es asín' $^{\prime 20}$.

Estos derechos y, en específico el que concierne al presente artículo, constituye una libertad preferida, en tanto dicho derecho resulta indispensable para la formación de una opinión pública, libre e informada, así como para el ejercicio de otros derechos fundamentales, como será desarrollado más adelante. En este orden de ideas, el Tribunal Constitucional ha expuesto que el concepto de libertad preferida no se encuentra referido a que el derecho de acceso a información pública sea más importante que otros derechos, sino a que todo acto o norma que incida o restrinja este derecho, carecerá de presunción de constitucionalidad y por lo tanto, deberá ser sometido a un control jurisdiccional más intenso. En el mismo caso, el Tribunal ha determinado que:

"(...) tratándose de una intervención legislativa sobre una libertad preferida, esta condición impone que el control sobre las normas y actos que incidan sobre ella no sólo se encuentren sujetos a un control jurisdiccional más intenso, a la luz de los principios de razonabilidad y proporcionalidad, sino, además, que en ese control tenga que considerarse que tales actos o normas que sobre él inciden carecen, prima facie, de la presunción de constitucionalidad.

Esta presunción de inconstitucionalidad de la ley que lo restringe se traduce en exigir del Estado y sus órganos la obligación de probar que existe un apremiante interés público por mantener en reserva o secreto la información pública solicitada y, a su vez, que sólo manteniendo tal reserva se puede servir efectivamente al interés constitucional que la justifica. De manera que si el Estado no justifica la existencia del apremiante interés público para negar el acceso a la información, la presunción que recae sobre la norma o acto debe efectivizarse y, en esa medida, confirmarse su inconstitucionalidad; pero también significa que la carga de la prueba

20 Sentencia del Tribunal Constitucional recaída en el Expediente 1797-2002-HD/TC, emitida el 29 de enero de 2003. 
acerca de la necesidad de mantener en reserva el acceso a la información ha de estar, exclusivamente, en manos del Estado"21.

En otras palabras, una libertad preferida implica que los actos o normas que la restringen se presumen inconstitucionales $y$, consecuentemente, el Estado está en la obligación de probar que existe un interés público urgente de mantener en reserva la información pública que se solicitó, razón por la cual es el Estado el que tiene la carga de probar dicho interés público y justificar adecuadamente las razones por las cuales no puede hacer entrega de la información.

Esto es de suma importancia para el desarrollo democrático de un país puesto que la democracia es, por definición, el gobierno del pueblo y el Estado se debe y está al servicio de aquel. La ciudadanía requiere información del Estado para poder tomar decisiones, guiar su vida y ejercer sus derechos, así como para controlar y fiscalizar la actuación estatal. Todos los cuales son elementos esenciales para hablar de una democracia plena.

\subsection{Herramienta necesaria para ejercicio de otros derechos}

El acceso a información pública es un derecho relacional o instrumental. Esto quiere decir que su protección y ejercicio es requerido para que otros derechos puedan verse igualmente satisfechos. En esta línea, el acceso a información pública es un mecanismo de empoderamiento de la ciudadanía para el ejercicio de sus demás derechos fundamentales.

Un primer derecho con el cual está absolutamente vinculado el derecho de acceso a información es el derecho de participación, por ejemplo, "en la medida que obliga a las autoridades a informar sobre el uso de los fondos públicos"22. Como contracara, contar con información pública es sumamente importante para que los ciudadanos puedan conocer y analizar si es que las autoridades se encuentran llevando a cabo su función de forma adecuada. En este sentido, cuando un individuo accede a información pública por la cual descubre que, por ejemplo, una obra o una función pública no se encuentra siendo desplegada de forma idónea, el ciudadano podrá en ese momento exigir que sus autoridades rindan cuentas sobre el manejo de su cargo público y su gestión. Sin información no es posible exigir al Estado el respeto de los derechos ni del adecuado funcionamiento de la administración pública.

21 Sentencia del Tribunal Constitucional recaída en el Expediente 1797-2002-HD/TC, emitida el 29 de enero del 2003.

Defensoría del Pueblo, Informe Defensoría 96: Balance a dos años de vigencia de la Ley de Transparencia y Acceso a la Información Pública, Lima, 2005, p. 17. Disponible en: http://www.defensoria.gob.pe/temas.php?des=8. Última fecha de consulta: 29 de octubre de 2016. 
También permite que el derecho a la libertad de expresión sea ejercido y es que solo cuando se cuenta con información necesaria y adecuada, es posible emitir una opinión o manifestar información en relación a hechos que, en este caso específico, estén vinculados al ejercicio de la función pública o a la administración pública en general.

\subsection{Herramienta necesaria para la prevención e investigación de la corrupción}

El acceso a información pública es muy relevante también porque es un mecanismo de control de la gestión estatal y, por consiguiente, permite prevenir y también investigar casos de corrupción pública. En torno a este punto, en doctrina se ha anotado que:

"Es importante tener claro que el acceso a la información no es sólo un derecho que todos tenemos sino también una herramienta de transparencia de la gestión estatal. En muchas entidades públicas pueden verse aún algunos rezagos de épocas anteriores en las que reinó la cultura del secreto. En ese sentido, todavía existen muchos funcionarios que prefieren no brindar información por temor a ser sancionados por sus superiores y optan por consultarlo todo, entorpeciendo así el acceso a la información. Esto conlleva también una falta de transparencia en la gestión gubernamental que no hace sino incrementar la distancia existente entre representantes y representados ${ }^{\prime 23}$.

En efecto, la corrupción y opacidad genera desconfianza de parte de la ciudadanía hacia sus autoridades. Por esa razón, la transparencia es vista como un mecanismo de prevención y supresión de la corrupción pues, cuando las reglas para la toma de decisiones gubernamentales son claras y la información al respecto es accesible, hay menor espacio y oportunidad para los funcionarios públicos que pretendan hacer un uso indebido del poder público ${ }^{24}$. En otros términos, habrá menos incentivos para cometer actos de corrupción, si es que los funcionarios y autoridades públicas saben que la ciudadanía está atenta permanentemente a sus decisiones y que los ciudadanos pueden solicitar en cualquier momento información pública que puede dar luces o revelar irregularidades en la toma de decisiones.

Pues bien, en materia de prevención y proscripción de la corrupción, el Perú es parte de la Convención de Naciones Unidas Contra la Corrupción, la cual es el tratado más

23 Fernández, Lucía, Transparencia y acceso a la información pública, Palestra, Lima. Disponible en: http://ipys.org/sites/default/files/articulo_lucia_fernandez.pdf. Última fecha de consulta: 29 de octubre de 2016. Corruption. Citado por: CASTRO, Alberto. Buen Gobierno y derechos humanos. Nuevas perspectivas en el derecho público para fortalecer la legitimidad de la administración pública en el Perú. Facultad de Derecho PUCP. Lima. 2014. p. 153. 
reciente y completo en materia de prevención y lucha contra la corrupción. Este tratado contempla disposiciones referidas a la importancia de que la ciudadanía acceda a información que el Estado posee a fin de mantener la vigilancia sobre la gestión gubernamental. Así, el artículo 13 referido a la participación de la sociedad, establece que:

"1. Cada Estado Parte adoptará medidas adecuadas, dentro de los medios de que disponga y de conformidad con los principios fundamentales de su derecho interno, para fomentar la participación activa de personas y grupos que no pertenezcan al sector público, como la sociedad civil, las organizaciones no gubernamentales y las organizaciones con base en la comunidad, en la prevención y la lucha contra la corrupción, y para sensibilizar a la opinión pública con respecto a la existencia, las causas y la gravedad de la corrupción, así como a la amenaza que ésta representa. Esa participación debería reforzarse con medidas como las siguientes:

a) Aumentar la transparencia y promover la contribución de la ciudadanía a los procesos de adopción de decisiones;

b) Garantizar el acceso eficaz del público a la información;

c) Realizar actividades de información pública para fomentar la intransigencia con la corrupción, así como programas de educación pública, incluidos programas escolares y universitarios;

d) Respetar, promover y proteger la libertad de buscar, recibir, publicar y difundir información relativa a la corrupción. Esa libertad podrá estar sujeta a ciertas restricciones, que deberán estar expresamente fijadas por la ley y ser necesarias para:

i) Garantizar el respeto de los derechos o la reputación de terceros;

ii) Salvaguardar la seguridad nacional, el orden público, o la salud o la moral públicas.

$(\ldots)^{\prime 25}$.

Esta norma es muy importante pues en ella puede apreciarse la relación estrecha que existe entre el derecho de acceso a información pública, el principio de transparencia y el derecho de participación ciudadana. Uno de ellas no funciona sin los otros dos. De igual manera, estos tres elementos son fundamentales para emprender acciones y planes de prevención de la corrupción eficaces.

25 Convención de Naciones Unidas contra la Corrupción. Resolución 58/4 de la Asamblea General de 31 de octubre de 2003. Disponible en: https://www.unodc.org/pdf/corruption/publications_unodc_convention-s.pdf. Última fecha de consulta: 29 de octubre de 2016. 
Otro aspecto digno de resaltar en esta norma es la referencia expresa a que el acceso a información pública debe ser eficaz. Esto quiere decir que para que el contenido del derecho se vea satisfecho realmente, la persona solicitante debe no solo poder iniciar y realizar el trámite de solicitud de información, sino que debe acceder de modo efectivo al contenido de la información que requiere. Solo accediendo o teniendo conocimiento del contenido del documento que se solicita, se puede empezar a fiscalizar los actos de gobierno. Para que sea eficaz, además, el procedimiento o trámite debe ser expedito, no oneroso (solo se cobrará el precio correspondiente a la copia o reproducción de la información) y lo menos formalista posible.

Adicionalmente, pero no menos importante, es el papel que cumple la transparencia y el acceso a información de cara a la investigación de casos de corrupción. En este sentido, este derecho adquiere especial relevancia cuando se necesita acceder a información o documentos de procesos penales seguidos contra funcionarios públicos por delitos de corrupción. De hecho, el artículo 139 de la Constitución dispone que todos los procesos por responsabilidad de funcionarios del Estado son siempre públicos. En relación a este punto, cabe dejar en claro que:

"cuando la Constitución y el Informe Defensorial 96 utilizan el concepto "procesos judiciales", están haciendo referencia a un proceso penal que, por su naturaleza acusatoria, cubre no sólo la etapa de juzgamiento, sino también la de investigación fiscal. Esta idea cobra mayor importancia si se toma en cuenta que la investigación se ha convertido en la parte esencial del proceso penal, toda vez que muchos casos se deciden en la etapa de la investigación fiscal a través de archivamientos. Entonces, resulta lógico y coherente afirmar que el principio de publicidad extraprocesal permite a la ciudadanía tener conocimiento de cómo desempeña el Ministerio Público su actividad persecutoria. Esta característica será fundamental en los casos de corrupción, en tanto que es el propio Estado quien debe perseguirse a sí mismo"26.

Todo esto es de suma relevancia en tanto la lucha contra la corrupción constituye un interés y mandato constitucional y así lo ha establecido el Tribunal Constitucional en diversa jurisprudencia ${ }^{27}$.

26 Rodríguez Vásquez, Julio, Ley de Transparencia y Acceso a la Información Pública: a 11 años de la publicación de un importante mecanismo de prevención de la corrupción, Instituto de Democracia y Derechos Humanos de la Pontificia Universidad Católica del Perú. Disponible en: http://idehpucp.pucp.edu.pe/comunicaciones/opinion/ley-detransparencia-y-acceso-a-la-informacion-publica-a-11-anos-de-la-publicacion-de-unimportante-mecanismo-de-prevencion-de-la-corrupcion/. Última fecha de consulta: 29 de octubre de 2016.

27 Para mayor información, ver Sentencia del Tribunal Constitucional recaída en el Expediente 019-2005-AI/TC, Sentencia del Tribunal Constitucional recaída en el 


\section{Conclusiones}

1. El derecho de acceso a información pública es un derecho autónomo que consiste en que toda persona puede pedir información que se encuentra en posesión de las instituciones y organismos del Estado y, por consiguiente, este debe entregarla. Los supuestos de excepción taxativos por los cuales no se pueda entregar determinada información están contemplados en la Constitución y en la Ley 27806 Ley de Transparencia y Acceso a la Información Pública.

2. El acceso a información pública es también un derecho humano que encuentra protección en el ordenamiento jurídico internacional, a través de diversos tratados internacionales y también de jurisprudencia de instancias como la Corte Interamericana de Derechos Humanos.

3. La razón de ser de este derecho radica, en primer lugar, en el modelo democrático en el que se vive, por el cual el poder del Estado proviene del pueblo y, por ende, lo lógico es que el Estado no oculte nada a sus ciudadanos. En segundo lugar, y a consecuencia de esta premisa, el principio de publicidad o máxima divulgación es la base sobre la cual se protege y garantiza el derecho de acceso a información pública. En este mismo sentido, se encuentra estrechamente ligado al principio de transparencia, en su dimensión pasiva.

4. El derecho de acceso a información pública ha sido considerado por el Tribunal Constitucional como una libertad preferida, lo cual quiere decir que todo acto o norma que restrinja este derecho carece de presunción de constitucionalidad y, por lo tanto, debe ser sometido a un control jurisdiccional de mayor intensidad a efectos de corroborar que la entidad pública haya clasificado adecuadamente la información que negó al ciudadano.

5. El derecho de acceso a información pública no se ve satisfecho con la sola acción de presentar la solicitud y realizar el trámite correspondiente ante la entidad pública respectiva. Por el contrario, el derecho se ejercerá plenamente cuando la información solicitada es brindada a la persona solicitante. Lo importante es que el contenido de la información sea accesible. De lo contrario, el derecho de acceso a información pública carecería de sentido.

6. Este derecho tiene naturaleza instrumental de cara al ejercicio de otros derechos fundamentales como lo es el derecho de participación ciudadana, de rendición de cuentas y de libertad de expresión.

7. La importancia de este derecho humano radica también en que es un mecanismo fundamental para la prevención y lucha contra la corrupción. Y es

Expediente 009-2007-PI/TC, Sentencia del Tribunal Constitucional recaída en el Expediente 1271-2008-PH/TC y, Sentencia del Tribunal Constitucional recaída en el Expediente 017-2011-PI/TC. 
que cuando un Estado actúa sin opacidad y brindando acceso informativo eficaz a la ciudadanía, se generan menos incentivos para los funcionarios públicos que buscan hacer un mal uso de su poder público pues saben que la población se encuentra vigilante y fiscaliza sus actos y decisiones. 